\title{
Assembly Principles and Relaxation Processes in Nanosized Heterogeneous Complexes: Multiporphyrin Structures and CdSe/ZnS Nanocrystals
}

\author{
E. I. Zenkevich ${ }^{a}$ and C. von Borczyskowski ${ }^{b}$ \\ ${ }^{a}$ National Technical University of Belarus, pr. Nezavisimosti 65, Minsk, 220013 Belarus \\ e-mail:zenekv@tut.by \\ ${ }^{b}$ Institute of Physics, Chemnitz University of Technology, 09107 Chemnitz, Germany
}

Received September 8, 2009

\begin{abstract}
Based on the extra-ligand addition effect, the principles of targeted self-assembly of nanosized multiporphyrin complexes of various types with controllable geometry and composition (up to 8 tetrapyrroles) and heterogeneous composites based on trioctylphosphine oxide-stabilized CdSe/ZnS semiconductor nanocrystals and organic compounds were developed. The dynamics and mechanisms of energy and charge transfer (including electron tunneling) in such systems were studied by continuous, picosecond fluorescence $\left(\Delta_{1 / 2} \approx 30 \mathrm{ps}\right)$, and femtosecond transient $\left(\Delta_{1 / 2} \approx 120 \mathrm{fs}\right)$ spectroscopy with varying the quantitative and qualitative constitution of the composites, the temperature, and the polarity of the medium.
\end{abstract}

DOI: $10.1134 / \mathrm{S} 0018143909070121$

It is commonly accepted that nanotechnology is a combination of processes that make it possible to fabricate and to study devices and materials on the atomic, molecular, or macromolecular scale with a size of $\leq 100 \mathrm{~nm}$ and substantially different properties as compared to larger entities. The principal property of nanostructures is the specific size dependence of their physicochemical characteristics

Considerable progress in the development of functional nanoassemblies based on the bottom-up strategy [1] has been made over the last decade in both basic and applied aspects. The implementation of this strategy is based on (1) the principles of supramolecular chemistry; i.e., self-assembly of organic molecules into structurally organized entities [2]; (2) methods of organometallic synthesis of semiconductor nanocrystals of various dimensions and structures [3]; and (3) the formation of ìnanocrystal-organic ligandî heterogeneous composites using various techniques $[4,5]$.
In this paper, we summarize the latest results $[4,6-$ 10] of the Belarusian-German cooperation in the field of the target formation of self-assembling, structurally organized, multicomponent organic and inorganic nanosized complexes with effective energy and/or charge transfer and investigation of their photophysics and photochemistry.

\section{EXPERIMENTAL}

The target formation of multiporphyrin complexes is based on the simultaneous use of both covalent binding (synthesis of chemical dimers and trimers of zinc octaethylporphyrins with the meso-phenyl spacer) and noncovalent self-assembling via the two-site coordination of the dimers and trimers to ligand molecules (meso-substituted porphyrins and chlorins) by the keylock mechanism [6-8] (Fig. 1, structures I-V). The surface of $\mathrm{CdSe} / \mathrm{ZnS}$ semiconductor nanocrystals of various dimensions (core diameter $d_{\mathrm{CdSe}}=2.1-5.2 \mathrm{~nm}$ containing two $\mathrm{ZnS}$ monolayers with a total thickness of

Fig. 1. Optimized (HyperChem, release 4.0, semiempirical PM3 method) structures of self-assembling multiporphyrin complexes, based on chemical dimers $(\mathrm{ZnOEP})_{2} \mathrm{Ph}$ or trimers $(\mathrm{ZnOEP})_{3} \mathrm{Ph}_{2}$ of zinc octaethylporhyrin and pyrydyl-substituted tetrapyrrole extra-ligands (I-V), and composites made from trioctylphosphine oxide-stabilized CdSe/ZnS semiconductor nanocrystals and porphyrin macrocycles (VI, VII). The $\beta$-ethyl substituent in the dimer $(\mathrm{ZnOEP})_{2} \mathrm{Ph}$ and trimer $\left(\mathrm{ZnOEP}_{3} \mathrm{Ph}_{2}\right.$ are not shown. The symbol $\otimes$ denote the subunits involved in the complexes. The sizes of the porphyrin and TOPO molecules, CdSe core, and $\mathrm{ZnS}$ monolayers are given on the actual relative scale. 
I: $\quad(\mathrm{ZnOEP})_{2} \otimes \mathrm{H}_{2} \mathrm{P}\left(\mathrm{m}^{\wedge} \mathrm{Pyr}\right)_{2}$

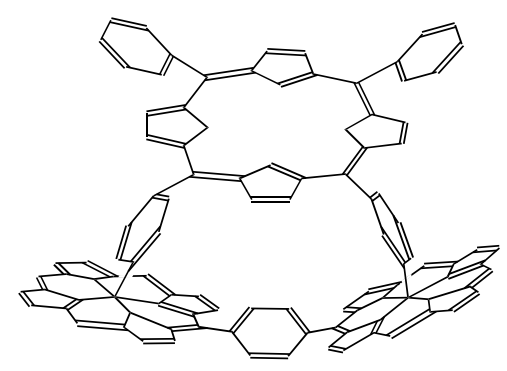

III: $\quad(\mathrm{ZnOEP})_{2} \mathrm{Ph}-\mathrm{Q} \otimes \mathrm{H}_{2} \mathrm{P}\left(\mathrm{m}^{\wedge} \mathrm{Pyr}\right)_{2}$

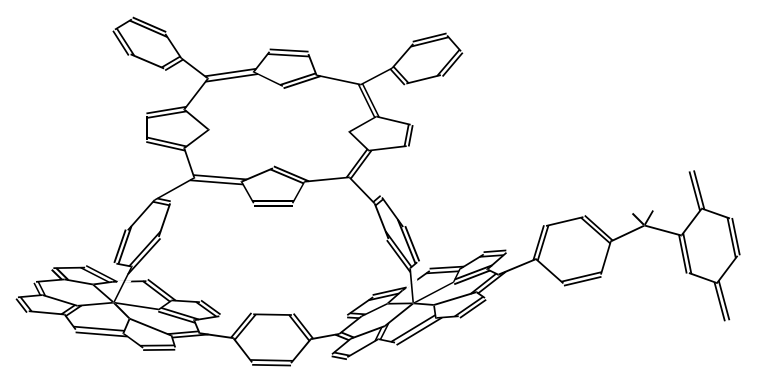

$\mathbf{V}$

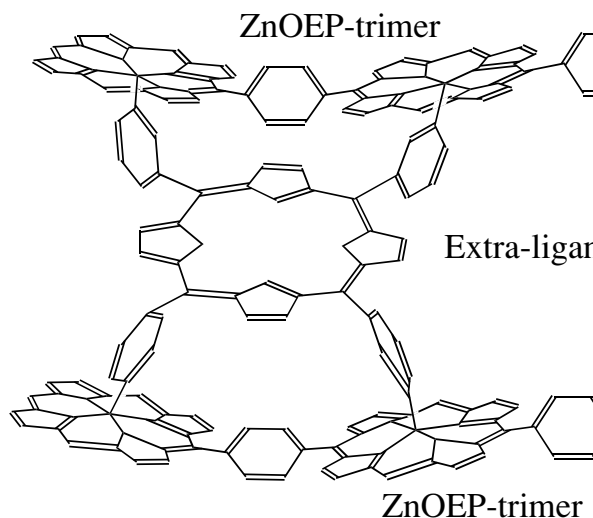

VI

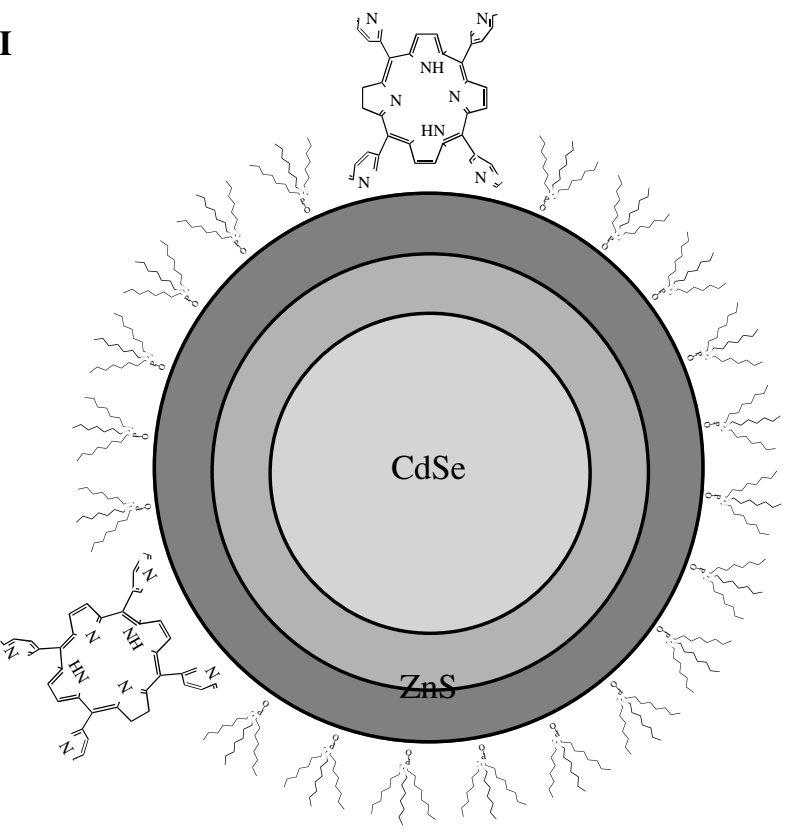

II: $\quad(\mathrm{ZnOEP})_{2} \otimes \mathrm{H}_{2} \mathrm{P}\left(\mathrm{m}^{\wedge} \mathrm{Pyr}\right)_{2}(5 \mathrm{~F}-\mathrm{Ph})_{2}$

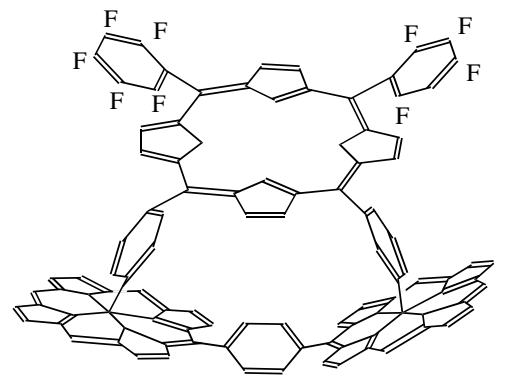

IV: $\quad 2(\mathrm{ZnOEP}){ }_{2} \mathrm{PhQ} \otimes(\mathrm{m}-\mathrm{Pyr})_{4} \mathrm{CuP}$

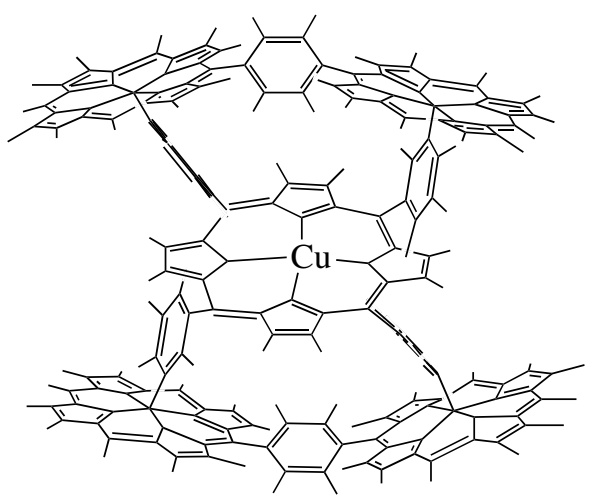

Extra-ligand 2

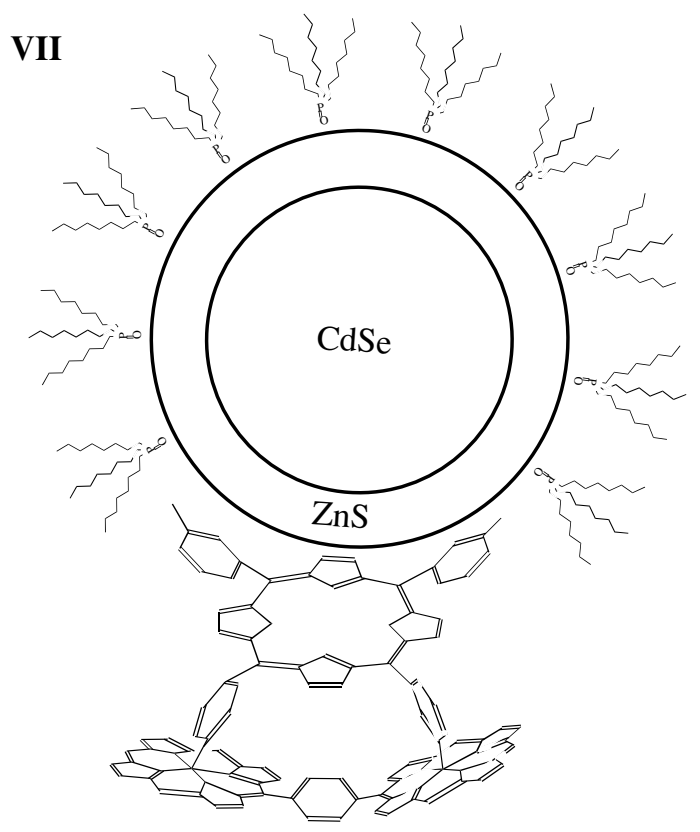



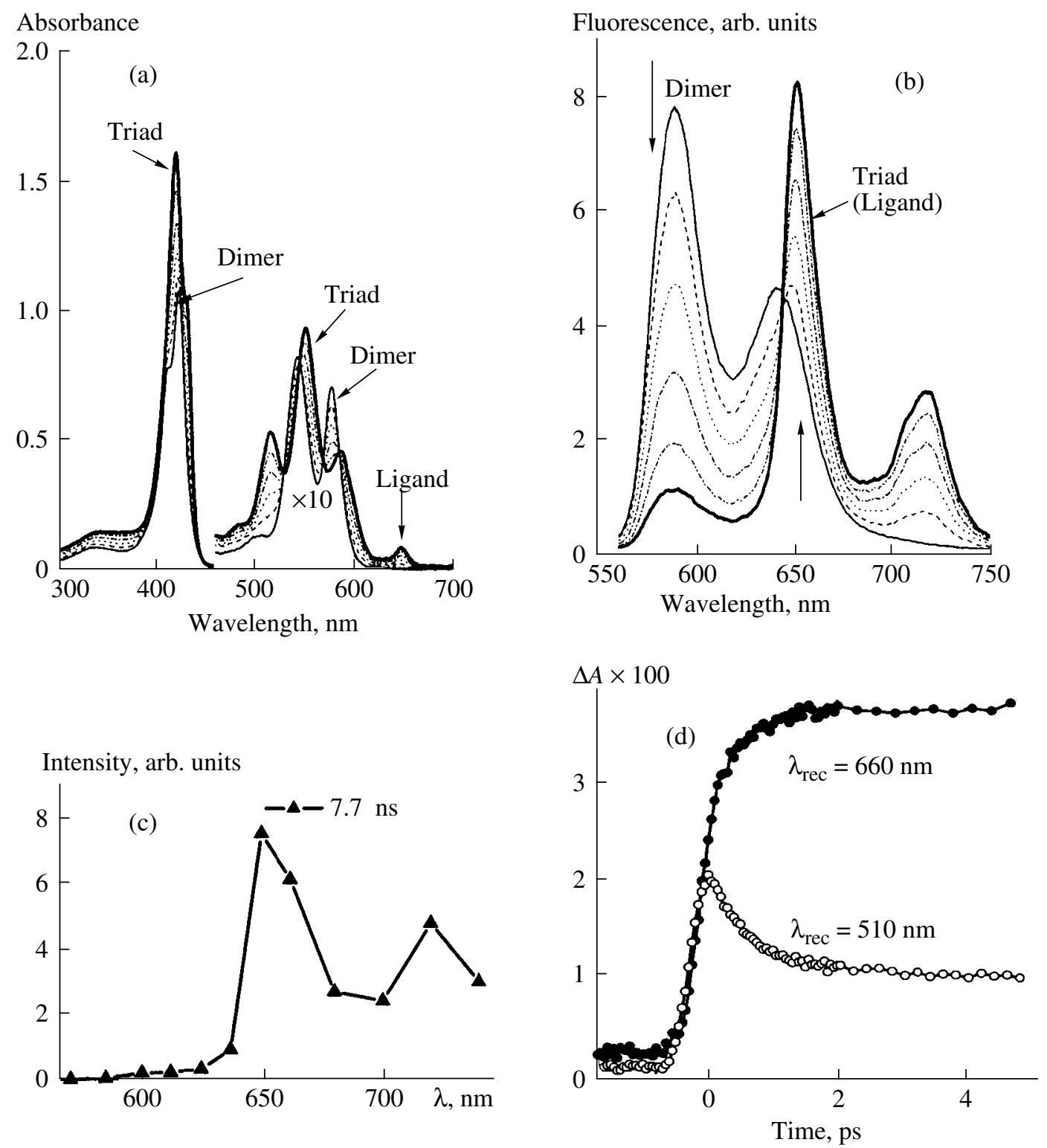

Fig. 2. Changes in the spectral-kinetic parameters of interacting subunits upon the formation of triads (toluene, $295 \mathrm{~K}$ ): (a) absorption and (b) fluorescence $\left(\lambda_{\mathrm{ex}}=546 \mathrm{~nm}\right)$ spectra of the dimer $(\mathrm{ZnOEP})_{2} \mathrm{Ph}$ during the titration with the extra-ligand $\mathrm{H}_{2} \mathrm{P}(\mathrm{m}-\mathrm{Pyr}){ }_{2}$; (c) the amplitude distribution of the decay time for the extra-ligand in the triad $(\mathrm{ZnOEP})_{2} \mathrm{Ph} \otimes \mathrm{H}_{2} \mathrm{P}\left(\mathrm{m}^{\wedge} \mathrm{Pyr}\right)_{2}$ as found by global fit analysis of the results of 12 correlated-photon-counting measurements; and (d) the femtosecond kinetics of induced absorption of the $(\mathrm{ZnOEP})_{2} \mathrm{Ph} \otimes \mathrm{H}_{2} \mathrm{P}\left(\mathrm{m}^{\wedge} \mathrm{Pyr}\right)_{2}-(5 \mathrm{~F}-\mathrm{Ph})_{2}$ triad with the pentafluorinated extra-ligand.

$1 \mathrm{~nm}$ stabilized by trioctylphosphine oxide (TOPO) ${ }^{1}$ was passivated with molecules of pyridyl-substituted porphyrin ligands by employing the two-site binding effects as well [6-8] (Fig. 1, structures VI, VII). The comprehensive procedures for the synthesis of tetrapyrrole compounds and the experimental procedure for the formation of multiporphyrin complexes (more than 80 types) and "nanocrystal-porphyrin" nanocomposites (more than 20) are based on the titration experiments and are detailed in [4, 6-10], as well as the equip-

\footnotetext{
${ }^{1}$ TOPO was available from Evident Technologies Inc., Troy, NY, USA.
}

ment used and the measurement errors. The pathways, mechanisms, and dynamics of relaxation processes in the complexes in question were studied by continuous, picosecond fluorescence $\left(\Delta_{1 / 2} \approx 30 \mathrm{ps}\right)$, and femtosecond transient $\left(\Delta_{1 / 2} \approx 120 \mathrm{fs}\right)$ spectroscopy.

\section{RESULTS AND DISCUSSION}

Porphyrin triads (Fig. 1; structures I, II). In the ground $\mathrm{S}_{0}$ state, interaction between the components in triads I and II is weak and their absorption spectra retain the individual character (Fig. 2a). Upon photoexcitation of triad $\mathbf{I}$, the quenching of the excited $S_{1}$ state 
of the dimer $(\mathrm{ZnOEP})_{2} \mathrm{Ph}$ (Fig. $\left.2 \mathrm{~b}\right)$ is due to $\mathrm{S}-\mathrm{S}$ energy transfer (ET) by the Förster mechanism and the "dimer $\longrightarrow$ ligand" photoinduced electron transfer (PIET) over a time of $\sim 0.9 \mathrm{ps}$; competition between these pathways is controlled by varying the polarity and temperature of the solvent. For the same triad, it was found that the lifetime of the $S_{1}$ state of the ligand noticeably shortened (from 9.3 to 7.7 ns, Fig. 2c), which is associated with photoinduced hole transfer "ligand $\longrightarrow$ dimer" [6]. The dynamics of charge transfer (coherent and incoherent) in such complexes is described by the reduced density matrix method in terms of the Marcus model [7].

The femtosecond absorption study of triad II, which have the same structure as I with the only difference that it contains a pentafluorinated extra-ligand (strong electron acceptor), has shown that the effective quenching of the excited $S_{1}$ states of both the dimer and the extra-ligand is due to fast dimer $\longrightarrow$ ligand photoinduced electron transfer (PIET) over a time of $700 \pm$ $100 \mathrm{fs}$ (Fig. 2d). As a result, the low-lying $\left[\right.$ dimer $^{+} . .$. ligand $\left.{ }^{-}\right]$charge-transfer state is populated. It is essential that this electron transfer in triad II remains quite effective in rigid solutions at 77-120 K (the same situation is known for the reaction centers of in vivo photosynthesizing bacteria). Charge recombination in triad II is accompanied by population of the $\mathrm{T}_{1}$ state of the extra-ligand $\left(\tau_{\mathrm{T}}=6.4 \mu \mathrm{s}\right)$ with a high quantum yield [7].

Porphyrin tetrads containing covalently bound electron acceptors (benzoquinone $(\mathrm{Q})$, pyromellitimide (PIm)) (Fig. 1, structure III). As compared to triads $\mathrm{A}$, the luminescence of both the dimer and the ligand in the tetrads is quenched to a greater extent. The radiationless deactivation of the $S_{1}$ state of the dimer $(\mathrm{ZnOEP})_{2} \mathrm{Ph}$ is due to PIET onto the extra-ligand ( $\sim 0.9-1.7 \mathrm{ps}$ ), with the processes being much faster the "dimer $\longrightarrow$ Q, PIm" photoinduced electron transfer (34-135 ps, toluene, $295 \mathrm{~K})$. The unusually rapid deactivation of the $S_{1}$ state of the extra-ligand (from $\tau_{0}=$ $7.7 \mathrm{~ns}$ to $\tau_{\mathrm{S}}=0.94-2.6 \mathrm{~ns}$ ) in the tetrads is associated with two competing processes, the long-range $\left(\mathrm{r}_{\mathrm{DA}}=\right.$ 18-24 A) "ligand $\longrightarrow$ Q, PIm" photoinduced electron transfer via the superexchange mechanism and the ligand $\longrightarrow$ dimer photoinduced hole transfer followed by the superexchange processes of PIET onto low-lying CT levels $[6,10]$.

Pentad with $\mathrm{CuP}(\mathrm{m}-\mathrm{Pyr})_{4}$ extra-ligand (Fig. 1 structure IV). Based on the spectral-kinetic and temperature data (Fig. 3a), we have shown [7] that several physicochemical processes are responsible for the effective quenching of the pentad (Fig. 3b): (a) thermally activated $\mathrm{S}-\mathrm{S}$ energy transfer from the $\mathrm{S}_{1}$ level of the dimer to the nonfluorescing sing-doublet ${ }^{2} \mathrm{~S}_{1}$ level of the $\mathrm{CuP}(\mathrm{m}-\mathrm{Pyr})_{4}$ molecule $\left(\Delta \mathrm{E}=-580 \mathrm{~cm}^{-1}\right)$, (b) photoinduced electron transfer formation of the CT

state $\left[(\mathrm{ZnOEP})_{2} \mathrm{Ph}^{+} \ldots \mathrm{CuP}(\mathrm{m}-\mathrm{Pyr})_{4}^{-}\right]$, and (c) an increase in the probability of nonradiative intersystem crossing in the pentad components owing to $d-\pi$ exchange interactions of the unpaired d electron of the central atom $\mathrm{Cu}(\mathrm{II})$ with the $\pi$-conjugated tetrapyrrole macrocycles of two dimers and the extra-ligand. At $\mathrm{T} \leq$ $150 \mathrm{~K}$, fluorescence quenching of the dimer is in most part the manifestation of the $d-\pi$ effects.

Finlay, it should be noted that the self-assembly of multiporphyrin entities containing up to eight tetrapyrrole macrocycles was realized on the basis of the covalently bound trimers $(\mathrm{ZnOEP})_{3} \mathrm{Ph}_{2}$ (Fig. 1, structure V) [8]. We have experimentally and theoretically substantiated that there is competition between the energy transfer and photoinduced electron transfer processes in such complexes and this competition can be controlled by varying the spectral and redox properties of interacting chromophores, their binding sites in the assembly, and the polarity and temperature of the medium.

"Semiconductor CdSe/ZnS nanocrystal-porphyrin" nanocomposites (Fig.1; structures VI, VII). The formation of the heterogeneous ìnanocrystal-porphyrinî nanocomposites with a variable composition is manifested in the luminescence quenching of the nanocrystals (intensity decline and a rise of the shortlived components in the nonexponential decay kinetics), but it does not lead to fluorescence quenching of the attached porphyrin monomers (Fig. 4)) [4]. In [9], we have shown that the ligand-induced luminescence quenching of nanocrystals can be due to a process other than ET and PIET in character. This quenching depends on the size of the nanocrystals (Fig. 4d). It is caused by the inductive and mesomeric effects in the nanocrystalporphyrin nanocomposites and is associated (in the quantum-mechanical model) with nonzero values of the exciton wave functions of the both core $(\mathrm{CdSe})$ and shell $(\mathrm{ZnS})$. The porphyrin ligand can form specific local surface trapping states occurring in the band gap of the nanocrystal. For the CdSe/ZnS nanocrystals with different core diameters $d_{\mathrm{CdSe}}$ and two $\mathrm{ZnS}$ monolayers, the experimental values of the probability $k_{\mathrm{q}}$ of nanocrystal luminescence quenching by the $\mathrm{H}_{2} \mathrm{P}(\mathrm{m}-\mathrm{Pyr})_{4}$ porphyrin (as found from the Stern-Volmer quenching constants $K(x)$ agree well with the theoretical calculated trend of the square radial wave function $\psi^{2}(r)$ of $1 s$ electron $\left(1 \mathrm{~S}_{3 / 2}-1 \mathrm{~S}_{\mathrm{e}}\right)$ (solution of Schrodingerís equation for a spherical nanocrystal) (Fig. 5) [9]. In fact, such a dependence of nanocrystal luminescence quenching induced by one porphyrin molecule reflects the process of electron tunneling through the $\mathrm{ZnS}$ barrier onto the nanocrystal interfacial layer on the boundary with the surroundings. In this respect, single organic molecules bearing anchoring functional groups can be considered specific probes for investigation of complex physicochemical phenomena at the interface in semiconductor nanocrystals [11].

In conclusion, it should be pointed out that we have used this methodology for the formation and investiga- 


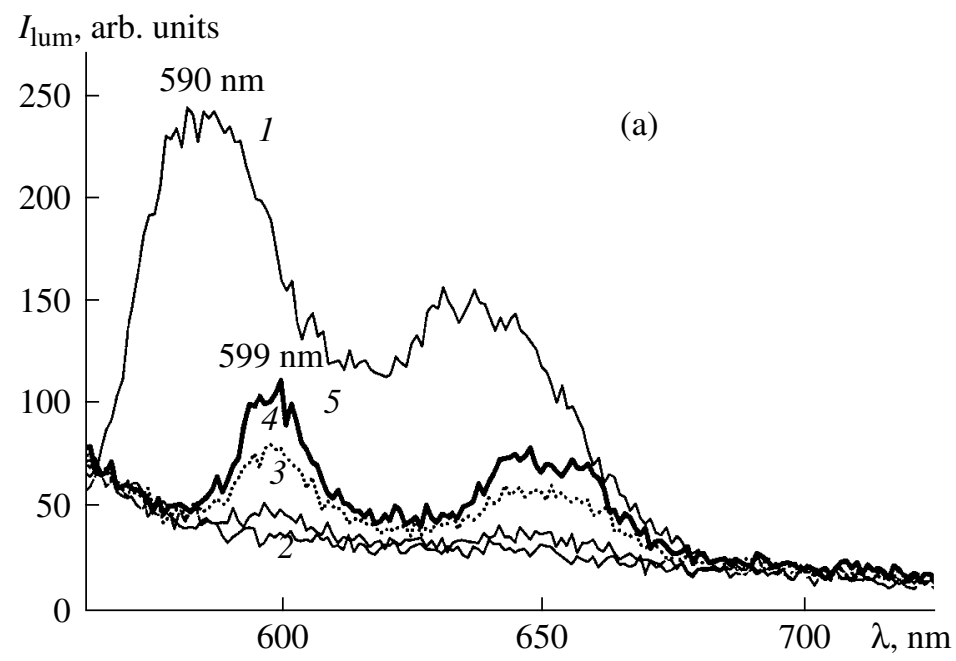

Energy transfer

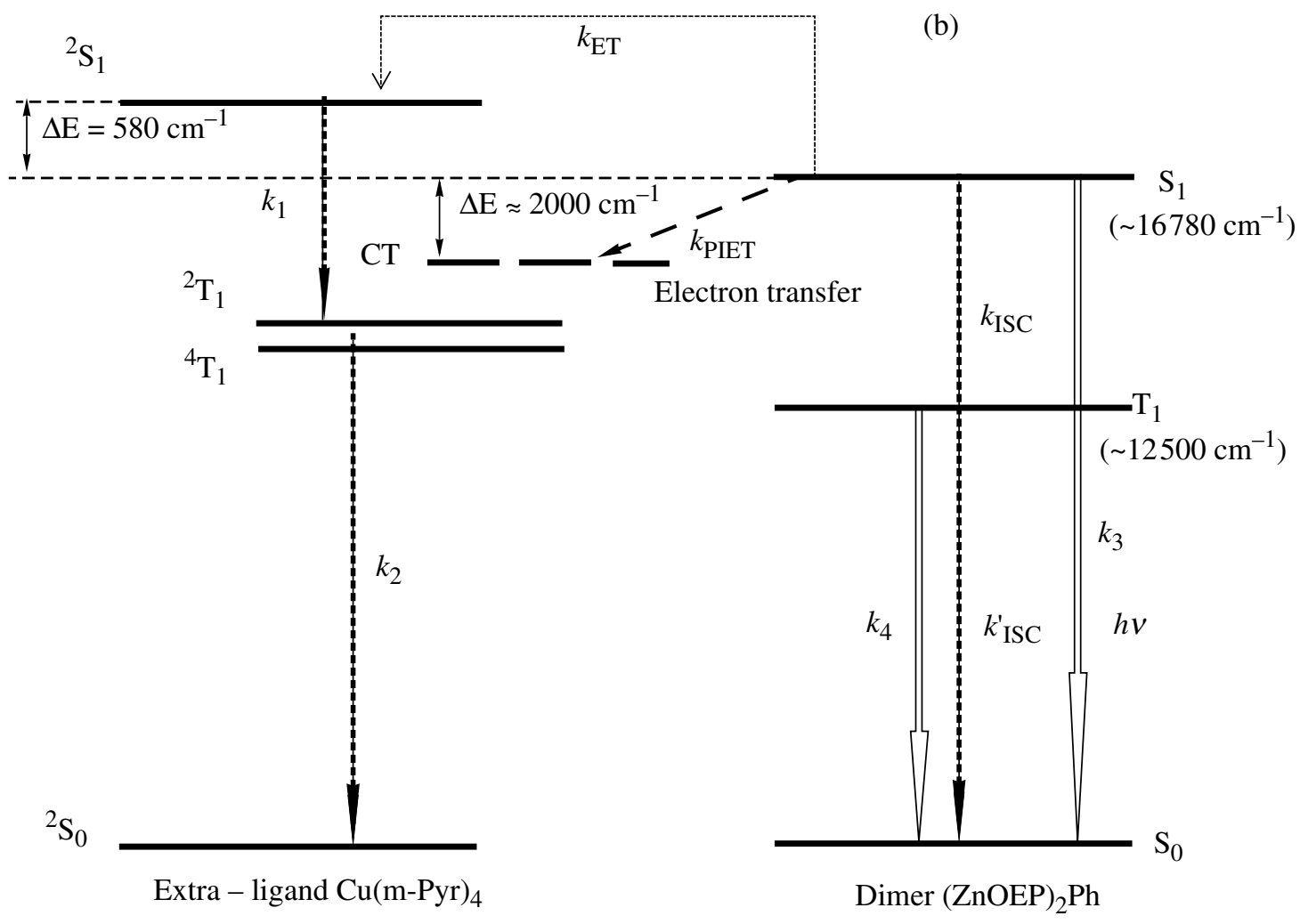

Fig. 3. (a) Fluorescence spectra at different temperatures $\left(\lambda_{\mathrm{ex}}=542 \mathrm{~nm}\right)$ and(b) the scheme of relaxation processes in the pentad $2\left[(\mathrm{ZnOEP})_{2} \mathrm{Ph}\right] \otimes \mathrm{CuP}(\mathrm{m}-\mathrm{Pyr})_{4}$. (a) (1) $300 \mathrm{~K}\left(\lambda_{\max }=590 \mathrm{~nm}\right.$ is due to the residual uncomplexed dimer), (2) 2120, (3) 190, (4) 165 , and (5) $150 \mathrm{~K}$. At $T \leq 210 \mathrm{~K}$, luminescence at $\lambda_{\max }=599 \mathrm{~nm}$ is the fluorescence of the dimer $(\mathrm{ZnOEP})_{2} \mathrm{Ph}$ in the pentad composition. (b) $k_{1}$ and $k_{2}$ are the probabilities of intersystem crossings ${ }^{2} \mathrm{~S}_{1} \sim \sim{ }^{2} \mathrm{~T}_{1}$ and ${ }^{2} \mathrm{~T}_{1} \sim \sim{ }^{2} \mathrm{~S}_{0}$, respectively, in the extra ligand; $k_{3}, k_{4}, k_{\text {ISC }}$, and $k_{\text {ISC }}^{\prime}$ are the probabilities of fluorescence $\mathrm{S}_{1} \longrightarrow \mathrm{S}_{0}$, phosphorescence $\mathrm{T}_{1} \longrightarrow \mathrm{S}_{0}$, and intersystem crossings $\mathrm{S}_{1} \sim \sim \mathrm{T}_{1}$ and $\mathrm{T}_{1} \sim \sim \mathrm{S}_{0}$ in the dimer, respectively; and $k_{\mathrm{ET}}$ and $k_{\mathrm{PIET}}$ are the of energy transfer and electron transfer probabilities, respectively. 

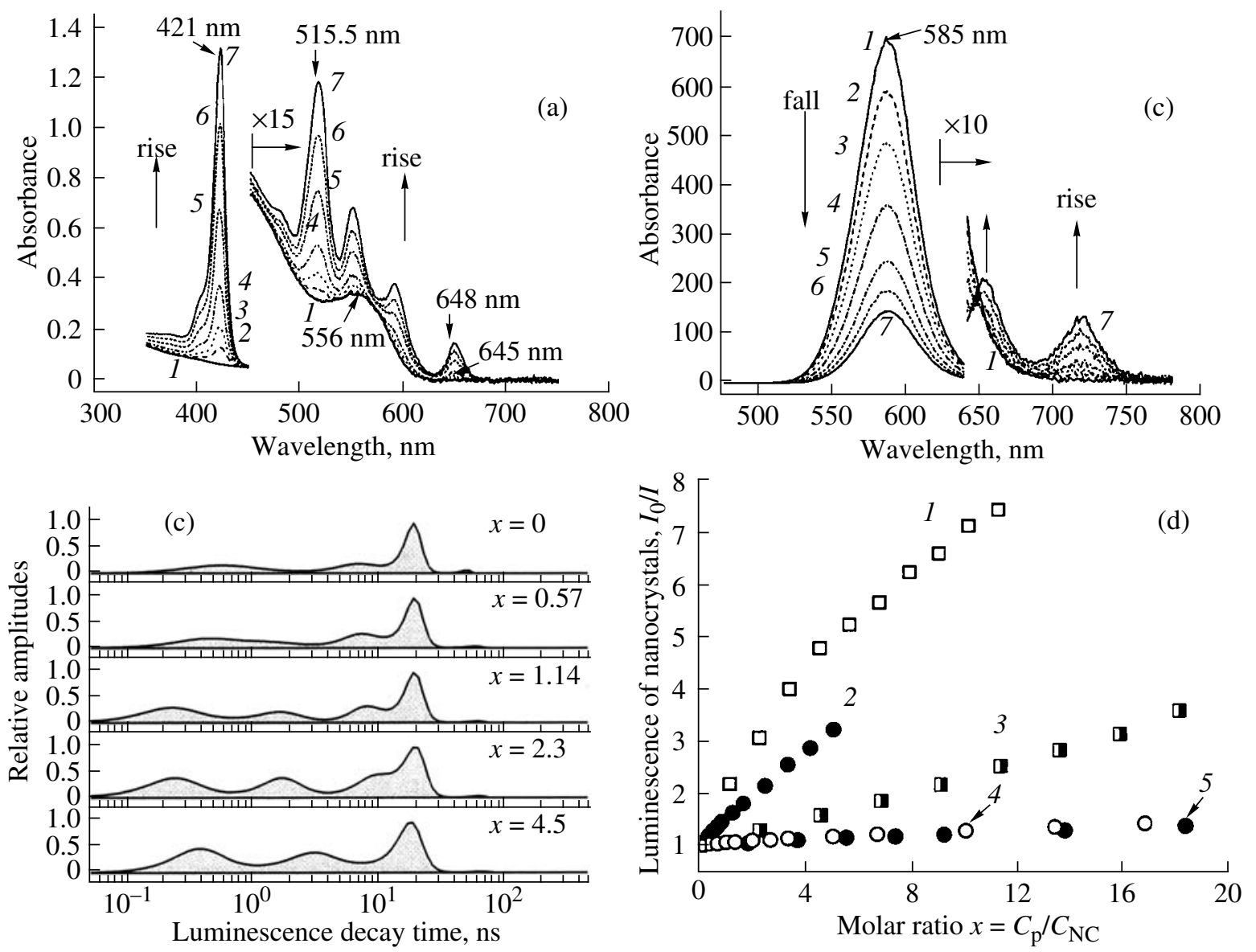

Fig. 4. (a) Absorption and (b) luminescence spectra, (c) the amplitude distribution of the decay kinetics, and (d) Stern-Volmer plots for the luminescence intensity of $\mathrm{CdSe} / \mathrm{ZnS}$ nanocrystals with an increase in the molar ratio $x=\left[C_{\text {porphyrin }}\right] /\left[C_{\text {nanocrystal }}\right]$ in toluene at $295 \mathrm{~K}\left(\lambda_{\mathrm{ex}}=460 \mathrm{~nm}\right)$. (a, b) $x=(1) 0.0$, (2) 1.15 , (3) 2.3 , (4) 4.5 , (5) 9.1 , (6) 13.5, and (7) 17.8. (c) $\lambda_{\mathrm{ex}}=575 \mathrm{~nm}$. $\lambda_{\mathrm{rec}}=585 \mathrm{~nm}$. (d) Ligand $\mathrm{H}_{2} \mathrm{P}\left(\mathrm{m}^{\wedge} \mathrm{Pyr}\right)_{4}$; parameters of nanocrystals: (1) the CdSe core diameter $d_{\mathrm{CdSe}}=3.5 \mathrm{~nm}$ and the number of ZnS monolayers (ML) $n=0 \mathrm{ML},(2) d_{\mathrm{CdSe}}=2.1 \mathrm{~nm}$ and $n=2 \mathrm{ML},(3) d_{\mathrm{CdSe}}=3.0 \mathrm{~nm}$ and $n=2 \mathrm{ML},(4) d_{\mathrm{CdSe}}=4.1 \mathrm{~nm}$ and $n=2 \mathrm{ML}$, and (5) $d_{\mathrm{CdSe}}=$ $5.2 \mathrm{~nm}$ and $n=2 \mathrm{ML}$.

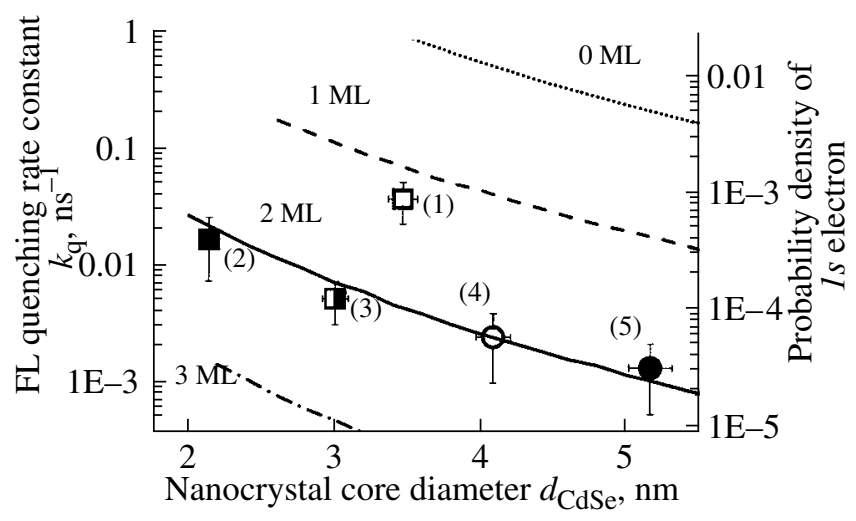

Fig. 5. Fitting the experimental values for the rate constants of luminescence quenching $\left(k_{q}\right)$ of CdSe/ZnS nanocrystals by $\mathrm{H}_{2} \mathrm{P}\left(\mathrm{m}^{\wedge} \mathrm{Pyr}\right)_{4}$ porphyrin molecules with the calculated values of the radial probability density function $\left(\psi^{2}(r)\right.$ of $1 s$ electron $\left(1 \mathrm{~S}_{3 / 2}{ }^{-}\right.$ $\left.1 \mathrm{~S}_{\mathrm{w}}\right)$ at the boundary of the nanocrystals with the surroundings, depending on the nanocrystal diameter $d_{\mathrm{CdSe}}$ and the number of $\mathrm{ZnS}$ monolayers. The geometrical and structural parameters of the nanocrystals for data points 1-5 are specified in Fig. 4. 
tion of the properties of nanocomposites based on $\mathrm{CdSe} / \mathrm{ZnS}$ nanocrystals capped with porphyrin triads (Fig. 1, VII) [10].

\section{ACKNOWLEDGEMENTS}

This work was supported by Volkswagen, grant no. I/79 435; ECONET, grant no. $18905 Y \mathrm{YD}$; and the Belarus National Program for Integrated Research, project Nanotekh-6.18.

\section{REFERENCES}

1. Yrvhoim, J., Srinivassarao, M., and Tolbert, L.M., J. Am. Chem. Soc., 2009, vol. 131, no. 2, p. 398.

2. Calzaferri, G. and Lutouskaya, K., Photochem. Photobiol. Sci., 2008, vol. 7, p. 879.

3. Semiconductor Nanocrystal Quantum Dots (Synthesis, Assembly, Spectroscopy and Applications), Rogach, A.L., Ed., Wien: Springer, 2008.
4. Zenkevich, E., Shulga, A., Cichos, F., Petrov, E., Blaudeck, T., and von Borczyskowski, C., J. Phys. Chem. B, 2005, vol. 109, no. 18, p. 8679.

5. Clapp, A.R., Medintz, I.L., and Mattoussi, H., Chem. Phys. Chem., 2006, vol. 7, p. 47.

6. Zenkevich, E.I., von Borczyskowski, C., Shulga, A.M., Bachilo, S.M., Rempel, U., and Willert, A., Chem. Phys., 2002, vol. 275, nos. 1-3, p. 185.

7. Zenkevich, E.I and von Borczyskowski, C., in Handbook of Polyelectrolytes and Their Applications, Tripathy, S.K., Kumar, J., and Nalwa, H.S., Eds., Amer. Sci. Publishers, 2002, vol. 2, p. 301.

8. Zenkevich, E.I., von Borczyskowski, C., and Shulga, A.M., J. Porphyrins Phthalocyanines, 2003, vol. 7, no. 11, p. 731.

9. Blaudeck, T., Zenkevich, E., Cichos, F., and von Borczyskowski, C., J. Phys. Chem. B, 2008, vol. 112, no. 51, p. 20251.

10. Zenkevich, E., Cichos, F., and von Borczyskowski, C., Macroheterocycles, 2009, vol. 2, no. 2, p. 57.

11. Jhonsi, M.A., Kathiravan, A., and Renganathan, R., J. Lumin., 2009, vol. 129, p. 854. 